Volume 1, Number 2, July 2019

\title{
Original article \\ Platelet rich plasma is better than corticosteroid in longterm outcome in planter fasciitis: A study in a tertiary level teaching hospital at Dhaka, Bangladesh

\author{
Md. Johurul Hoque , ${ }^{1}$ Muhammad Emam Zaman, ${ }^{2}$ Ripon Kumar Das, ${ }^{3}$ Mohammad Sayeed AL Mahmud, ${ }^{4}$
} Mahbuba Khatun 5
}

\begin{abstract}
This is a prospective comparative study to compare the efficacy of PRP injection versus corticosteroid injection for planter fasciitis. 35 male and 25 female (Mean Age 35.5 yrs.) presenting with planter fasciitis were randomized to receive there Platelet-rich plasma (PRP) injection ( $2 \mathrm{ml}$ PRP with $2 \mathrm{ml}$ of $2 \%$ xylocaine) given by a single surgeon. Patients were assessed before (Days0) and after (Days 30, 60, 90) treatment for chronic heel pain more than 6 months. Patients where followed up 1 year to assess heel pain over the calcaneal tuberocity. In the present study of 60 patients there were 35 male and 25 female. In the present study of 60 patients the mean age was 35.5 years (Range between 35 to 65 years). Infection, rupture of plantar fascia, heel pad atrophy and neurovascular damage where not found. Five patient reported pain for unto 9 days after PRP injection. In both groups heel pain improved dramatically after treatment, but the mode of improvement different. Compared with PRP injection. Corticosteroid injection improve at a faster rate over the first 30 days and then started to decline slightly until 90 days. After PRP injection heel pain, function improve steadily and where eventually better. PRP injection and Corticosteroid injection 30 days and faster rate 60 days of both group P-Value 0.0001. Almost high grater rate 60 days, group comparison with heel pain and function of the patients. PRP was more effective over the long term follow up period then corticosteroid injection in improving heel pain and function. That's way we recommend PRP in a first line injection treatment because it is very simple, cheap and more effective.
\end{abstract}

Keywords: PRP Injection, heel pain, planter fasciitis, corticosteroid injection

\section{Introduction}

Platelet-rich plasma (PRP) uses injections of a degree of a patient's own platelets to accelerate the healing of degenerated tendons, ligaments, muscles and joints. During this approach, PRP injections use every individual patient's own healing system to boost contractor issues. PRP injections are prepared by taking anyplace from one to a number of tubes of your own blood and running it through a centrifuge to concentrate the platelets. These activated platelets are then injected directly into your degenerated or unhealthy body tissue. Chronic heel pain is one of the most common disorders of the foot, the exact cause of which is still not known. ${ }^{[1]}$ Degenerative changes of the Plantar fasciitis due to repetitive microtrauma at the origin of plantar fascia are the common findings in heel pain. ${ }^{[2,3]}$ Stiell in 1922 stated, that heel pain is a condition which is yet to be treated efficiently as the causation is not known exactly. ${ }^{[4]}$ Lapidus and Guidotti, stated that the name painful heel is used deliberately since the cause of this definitive clinical entity still remains unknown. ${ }^{[5]}$ This entity of painful heel still remains a dilemma for the treating doctor. Woolnough called the entity "tennis heel", and postulated that repeated traction with aging and repeated trauma produces microscopic tears and cystic degeneration in the origin of the plantar fascia and the flexor digitorum brevis immediately beneath the plantar fascia ${ }^{[6]}$ Schon and Baxter concluded that in a few patients a neurogenic cause, involving entrapment of first branch of the lateral plantar nerve to the abductor digiti minimi, is associated with painful heel syndrome. [7] The diagnosis of plantar fasciitis is mainly clinical as the etiology is often not clear. Most often the patients are between 35-65 years of age. ${ }^{[8]}$ Patients usually complain of pain beneath the heel that is more on rising in the morning or after sitting for a while. As the patient starts walking the pain diminishes, and the patient is comfortable during the day. The most common clinical finding is a localised tenderness at the inferomedial aspect of the

1. Associate Professor, Department of Orthopedic, Zainul Haque Sikder Womens Medical College \& Hospital, Dhaka

2. Registrar, Orthopedics, Zainul HaqueSikder Women's Medical College \& Hospital, Dhaka

3. Assistant Professor, Department of Orthopedic, Zainul Haque Sikder Womens Medical College \& Hospital, Dhaka

4. Medical Officer, Norsingdi Sadar Hospital, Dhaka

5. OSD, Department of Surgery, Bangabandhu Sheikh Mujib Medical University, Dhaka.

\section{Address of Correspondence:}

Md. Johurul Hoque, Associate Professor, Department of Orthopedic, Zainul Haque Sikder Womens Medical College \& Hospital, Dhaka. 
calcaneal tuberosity. ${ }^{[1,9]}$ Various treatment modalities are available for this condition like rest, rigid or non-rigid orthosis, plantar fasciitis stretching exercises, ultrasound, extra-corporeal shock wave therapy, anti- inflammatory medications, local steroids, local autologous blood or platelet rich plasma injections and surgery in selected patients. ${ }^{[10-12]}$

Use of local steroid injections are superior in onset of action; however, rupture of plantar fascia and atrophy of heel found 15 women received PRP injection. Whereas 15 men and 20 women received corticosteroid injection. All patients completed the 1 year follow up.

Table 1: Distribution patients of age groups $(n=60)$.

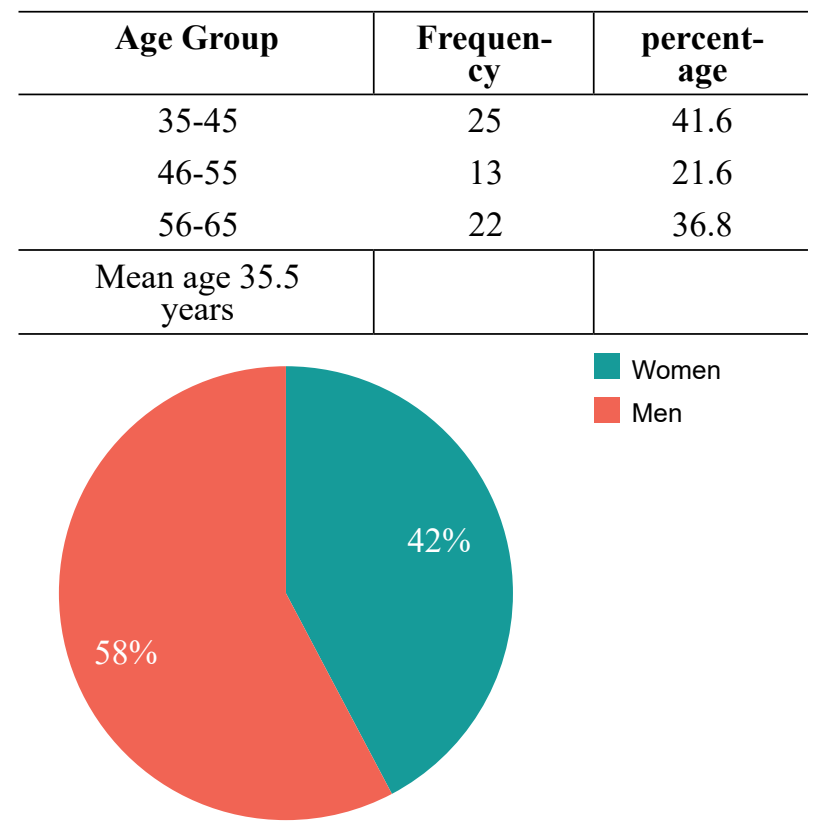

Fig 1: Sex distribution study of patients.

Table 2: characteristics of both groups $(n=60)$

\begin{tabular}{c|c|c|c}
\hline Category & PRP(N=25) & $\begin{array}{c}\text { Triamcinolone } \\
\text { Acetonide } \\
\text { corticosteroid } \\
\text { injection (N=35) }\end{array}$ & $\begin{array}{c}\mathbf{P} \\
\text { value }\end{array}$ \\
\hline $\begin{array}{c}\text { Age (years) } \\
\text { No of male: Fe- } \\
\text { male }\end{array}$ & $35 \pm 2.1$ & $42 \pm 7.3$ & 0.095 \\
$\begin{array}{c}\text { No of left: right } \\
\text { side }\end{array}$ & $3: 2$ & $4: 3$ & 0.400 \\
\hline
\end{tabular}

Table 3: Physical Demands of patient's comparison $(n=60)$

\begin{tabular}{c|c|c|c|c}
\hline Sedentary & Light & Medium & Heavy & Very heavy \\
\hline 1 & 1 & 10 & 1 & 2 \\
2 & 0 & 11 & 1 & 4 \\
\hline
\end{tabular}

No complication was noted. In both groups heel pain, function improved dramatically after treatment but the mode of improvement differed compared with PRP injection, corticosteroid injection improved two scores at a faster rateafter the first 30 days and then started to decline slightly until 60 day. After PRP injection two score (Pain and function) improved steadily and were much better (table 4).

Table 4: Group comparison with heel pain, function $(n=60)$

\begin{tabular}{ccccccc}
\hline Category & Day 0 & Day 30 & Day 60 & Day 90 & P value \\
\hline \multicolumn{7}{c}{ Heel pain: } \\
PRP & $5.9 \pm 1.2$ & $4.3 \pm 1.2$ & $3.5 \pm 1.1$ & $1.1 \pm 1.0$ & 0.0001 \\
Corticosteroid injection & $5.8 \pm 1.1$ & $1.6 \pm 0.8$ & $1.5 \pm 1.0$ & $2.7 \pm 1.0$ & 0.0001 \\
p value & 0.578 & 0.0001 & 0.0001 & 0.0001 \\
\hline PRP & $65.6 \pm 11.7$ & $50.2 \pm 15.2$ & $30.3 \pm 10.2$ & $18.2 \pm 8.1$ & 0.0001 \\
Corticosteroid injection & $60.1 \pm 12.4$ & $15.5 \pm 8.6$ & $20.0 \pm 10.2$ & $30.5 \pm 16.5$ & 0.0001 \\
p value & 0.155 & 0.0001 & 0.0001 & 0.0001 &
\end{tabular}

Table 4: VAS (visual analog scale) at 30 days and 
90 days for comparison to pain reduction to PRP and Steroid.

\begin{tabular}{c|c|c|c|c}
\hline \multirow{2}{*}{ VAS } & \multicolumn{2}{|c|}{ PRP $(\mathrm{n}=25)$} & \multicolumn{2}{c}{ Steroid $(\mathrm{n}=35)$} \\
\cline { 2 - 5 } & 30 days & 90 days & 30 days & $\begin{array}{c}90 \\
\text { days }\end{array}$ \\
\hline 0-3 (mild/pain free) & $8(32 \%)$ & $\begin{array}{c}20 \\
(80 \%)\end{array}$ & $\begin{array}{c}12 \\
(34 \%)\end{array}$ & $\begin{array}{c}25 \\
(71 \%)\end{array}$ \\
4-7 (moderate) & 15 & $5(20 \%)$ & 20 & 10 \\
& $(20 \%)$ & $57 \%)$ & $(28 \%)$ \\
8-10 (severe) & $2(.8 \%)$ & 3 & & \\
\hline Total & \multicolumn{3}{c}{25} & $35)$ \\
\hline
\end{tabular}

Discussion

Injection of PRP was more effective then corticosteroid injection in case of pain control, function. Decrease heel pain at 2 months was 90\% after PRP injection and 55\% after corticosteroid injection. Corticosteroid injection gives rapid recovery but temporary improvement in the first month. PRP injection stimulate the inflammatory cascade within the generated fascia, tendon sheath by providing cellular and humoral mediators for regeneration. Histological studies shows non inflammatory angiofibroblastic tendinosis,fibrosis, neurovascularization and mucoid degeneration in planter region. Alisara Arirachakaran et al. (2015) ${ }^{[22]}$ did a systematic review and network metaanalysis of randomized controlled trials, conducted with the aim of comparing relevant clinical outcomes between the use of PRP, autologous blood and corticosteroid injection. They concluded that the network meta-analysis provided additional information that PRP injection can improve pain and lower the risk of complications, whereas autologous blood injection can improve pain, disabilities scores and pressure pain threshold but has a higher risk of complications. The level of evidence of the study was Level I evidence. The result of the present study was that PRP injection significantly improves score. In this study after 6 months of PRP injection, when asked about overall subjective satisfaction among the patients of planter fasciitis. The PRP treatment should be adapted as a best of therapy for relief symptoms. Though this must be advised merely next other type of nonsurgical treatment failed because lower involvement of tools/ technologies \& fewer contact to blood products in other type of therapies ${ }^{[23-26]}$. The main findings of this study are that PRP injection resulted in better pain control and the improvement in functional outcome was stable and maintained up to a midterm follow-up. It is current opinion that the therapeutic activity of PRP is mainly due to the release of many growth factors (GFs), which can act on many aspects of fascia, tendon repair including angiogenesis, chemotaxis, and cell proliferation by activating intracellular signal-transduction pathways ${ }^{[25,26]}$. In the short term (1-33 months) effect, GFs can directly stimu- late fibro cyt e, tenocytes to produce extracellular matrix, and promote neofibrils formation and remodeling. Insulinlike GF-12 stimulates production of collagen [31]. in long-term (62- 122 months), depend on a direct stimulation, probably relies on the activation of resident tendon stem/progenitor cells (TSPCs), which have been recently identified in tendons tissue from different animal species. Like stem cells found in adult tissues, TSPCs are believed to be the source of recent differentiated fibro $\mathrm{c} \mathrm{yt}$ e, tenocytes, responsible for maintaining adequate fibrocyte,tenocyte numbers in the tissue throughout life and replenishing them after injury ${ }^{[27]}$. Regarding the amount of injection, Although smaller volume $3 \mathrm{ml}$ of PRP was injected in present study or even $1.52 \mathrm{ml}$ such as in previous study, the proportion of spread beyond fascia was little.so the amount of PRP is even $1.52 \mathrm{ml}$ is adequate to achieve good result on the other hand the greater volume of PRP could be an option. However, large volume can lead to further diffusion and require much more blood collection, which is undesirable. In our study, we not used ultrasonographic injection technique and the accuracy of injection was not to be guaranteed. Therefore, we increase the volume of injection up to $3 \mathrm{ml}$ so we can get maximum distribution of PRP in the area of maximal tenderness, in comprising with ultrasound injection which use $1.52 \mathrm{ml}$. Other therapies modalities want few expertise in contrast to injection PRP therapy. All staff should be good trained to make PRP from blood while this is not required in steroid injections or others. Corticosteroid injections have also been used for this problem, but studies showed that there is controversy about their efficacy ${ }^{[28]}$. Local corticosteroid injections in plantar fasciitis decreases both the pain and the inflammation. Rupture of plantar fascia and heel pad atrophy and other complications have been associated with corticosteroid use $[13,14$ ] but our study shows no such effects.

\section{complication.}

There is essential of long-time trials to found PRP as a best of treatment for long term permanent heal from fasciitis due to mechanical causes. The study was limited by a minor sample size and absence of a control group. Larger-scale randomized controlled studies are required to assistance elucidate PRP as a good management for this musculoskeletal injury.

Other modalities of treatment like extracorporeal shock wave therapy (ESWT) have been tried recently, however there is no conclusive data regarding its use. According to Saber et al, both local steroid injection and ESWT are proved to be effective in treatment of PF, but as steroid injection is more cost effective and has more reproducible results regardless of machine or operator, it is preferred. ${ }^{[18]}$ 


\section{Conclusion}

PRP injection is more effective then corticosteroid injection in improving pain, function. So that is why if recommend is as a first line treatment because it easy to push very effective for long term treatment. We believe that PRP injection should be offered to all patients suffering from planter fasciitis after failure of other conservative treatment. Further comparative studies with other type of injection or surgery are required to evaluate the longterm outcomes.

\section{Reference}

1. Goff JD, Crawford R. Diagnosis and treatment of plantar fasciitis. Am Fam Physician. 2011;84(6):676- 82.

2. Canale TS, Beaty HJ, Murphy AG. Disorder of tendons and fascia. Campbell's Orthopaedics. 11th ed. Philadelphia USA; 2008:4815-4818

3. Lemont H, Ammirati K, Usen N. Plantar fasciitis: a degenerative process (fasciosis) without inflammation. JAPMA. 2003;93:234-7.

4. Stiell WF. Painful heel. Practitioner. 1922;108:345.।

5. Lapidus PW, Guidotti FP. Painful heel: report of 323 patients with 364 painful heels. Clin Orthop. 1965;39:178-86.

6. Woolnough J. Tennis heel. Med JAus. 1954;2:857-61.

7. Schon LC. Plantar fascia and Baxter's nerve release. In Myerson M, ed: Current therapy in foot and ankle surgery, St Louis, 1993:177-182.

8. Schepsis A, Leach R, Gorzyca J. Plantar fasciitis: etiology, treatment, surgical results, and review of the literature. Clin Orthop. 1991;266:185-96.

9. Ryan MB, Wong AD, Gillies JH, Wong J, Taunton JE. Sonographically guided intra-tendinous injections of hyperosmolar dextrose/lidocaine: a pilot study for the treatment of chronic plantar fasciitis. Br J Sports Med. 2009;43;303-6.

10. Kim E, Lee JH. Autologous platelet-rich plasma versus dextrose prolotherapy for the treatment of chronic recalcitrant plantar fasciitis. PM\&R. 2014 Feb 28;6(2):152-8.

11. Crawford $\mathrm{F}$, Thomson $\mathrm{C}$. Interventions fortreating plantar heel pain. Cochrane Database Syst Rev. 2003;3(3):CD000416.

12. Landorf K, Menz H. Plantar heel pain and fasciitis. Clin Evid. 2008;2:1111.

13. Sellman JR. Plantar fascia rupture associated with corticosteroid injection. Foot Ankle Int. 1994;15:376- 81.

14. Acevedo JI, Beskin JL. Complications of plantar fascia rupture associated with corticosteroid injection. Foot Ankle Int. 1998;19:91-7.

15. Lee TG, Ahmad TS. Intralesional autologous blood injection compared to corticosteroid injection for treatment of chronic plantarfasciitis. A prospective, randomized, controlled trial. Foot Ankle Int. 2007;28:984-90.

16. Prichasuk S. The heel pad in plantar heel pain. J Bone Joint Surg Br. 1994;76:140-2.

17. Kauffman J. Plantar Fasciitis Medline Plus Medical Encyclopaedia. National Institutes Health. 2006;09-21.

18. Saber N, Diab H, Nassar W, Razaak HA. Ultrasound guided local steroid injection versus extracorporeal shockwave therapy in the treatment of plantar fasciitis. Alexandria J Med. 2011;48:35- 42.

19. Yesiltas F, Aydogan U, Parlak A. The comparison of intralesionary steroid injection and autologous venous blood injection in patients with plantar fasciitis. Acta Medica Mediterranea. 2015;3:711.

20. Vahdatpour B, Kianimehr L, Ahrar MH. Autologous platelet-rich plasma compared with whole blood for the treatment of chronic plantar fasciitis; a comparative clinical trial. Adv Biomed Res. 2016;5:84.

21. Ahmed Baba M, Mir BA, Halwai MA, Bbashir A, Rashid S Khursheed O. E valuation of the results of autologous blood injection in the treatment of refractory heel pain. The Foot and Ankle Online Journal. 2013;6(10).

22. K. The biology of platelet-rich plasma and its application in trauma and orthopaedic surgery: a review of the literature. J Bone Joint Surg Br. 2009; 91:987e996.

23. Cook JL, Purdam CR. Is tendon pathology a continuum? A pathology model to explain the clinical presentation of load-induced tendinopathy. Br J Sports Med. 2009; 42:40916.

24. Wilson JJ, Best TM. Common overuse tendon problems: a review and recommendations for treatment. Am Fam Physician. 2005; 72:811-8.

25. Sun Y, Feng Y, Zhang CQ, Chen SB, Cheng XG. the regenerative effect of platelet-rich plasma on healing in large osteochondral defects. Int Orthop. 2010; 34(4):589-97.

26. Fardale PD, Wiggens ME. Corticosteroid injections: their use and abuse. J Am Acad Orthop Surg. 1994; 2:133e140.

27. Bonnici AV, Spenser JD. Survey of "Trigger finger"?

28. Dohan Ehrenfest DM, Rasmusson L, Albrektsson T. Classification of platelet concentrates from pure platelet-rich plasma (P-PRP) to leucocyte- and platelet- rich fibrin (L-PRF). Trends Biotechnol. 2009; 27:158e167. 